\section{Reportagem e reconhecimento: a alteridade como projeto}

Reges Schwaab

\section{Resumo:}

O presente texto debate a reportagem jornalística e sua construção narrativa como devedora do gesto de reconhecimento, mantendo em permanente evidência o Outro como dimensão primeira da comunicação. O Outro como questão é um convite ao fim da distância, mesmo que seja também um limite à aproximação. Para Paul Ricoeur, a reciprocidade do reconhecimento é a exigência ética mais profunda. Em Emmanuel Lévinas, o princípio ético absoluto é o cuidado com o outro, uma responsabilidade incondicional e infinita como estrutura fundamental da subjetividade. Em uma articulação entre os estudos da reportagem e a filosofia, propôs-se tomar a reportagem, em sua qualidade de metodologia do jornalismo, fundamentada por um encontro que é ruptura do mesmo em direção ao Outro e cuja escrita pode tensionar a representação que apaga o clamor do Rosto, potência para pensar o jornalismo diante da vida precária e da exclusão.

Palavras-chave: Jornalismo. Narrativa. Reconhecimento.

\section{Reportage and recognition: the other otherness as a project}

\begin{abstract}
:
This article debates the journalistic reportage and its narrative construction as a debtor of the gesture of recognition, keeping the Other in constant evidence as the first communication dimension. The Other as a question is an invitation to ending distance and, at same time, it is a limit to approximation. For Paul Ricoeur, the reciprocity of recognition is the deeper ethical requirement. In Emmanuel Lévinas' work, the absolute ethical principle is taking care of the Other, an unconditional and infinite responsibility as a fundamental structure of subjectivity. From an articulation between the studies of reporting and philosophy, we propose to consider the reportage, in its condition as a methodology of journalism, based on an encounter that is a rupture of the same in direction to the Other, and whose writing can tension the representation that erases the clamor of the Face, a power to think about journalism and its relation to the precarious lives and exclusion.
\end{abstract}

Keywords: Journalism. Narrative. Recognition.
Recebido em: 22.07 .20

Aprovado em: 21.08.21

\section{Reges Schwaab}

Professor do Programa de Pós-Graduação em Comunicação e do Departamento de Ciências da Comunicação - Campus Frederico Westphalen Universidade Federal de Santa Maria. Realizou pós-doutorado na Universidad de Antioquia, em Medellín - Colômbia. Doutor em Comunicação e Informação pela Universidade Federal do Rio Grande do Sul, com estágio de doutoramento na Universidade Nova de Lisboa - Portugal. Mestre pelo mesmo programa. Graduado em Jornalismo pela Universidade Regional do Noroeste do Estado do Rio Grande do Sul.

E-mail: reges.ts@gmail. com 
${ }^{1}$ Conforme Marcelo (2011, p. 273), a luta por reconhecimento é tratada, costumeiramente, como

a "tentativa legítima de supressão desse sofrimento através da reivindicação social de direitos", o estabelecimento de uma exigência. No modelo de Axel Honneth (2003), há pelo menos três esferas de

reconhecimento: amor, direito e solidariedade. "O amor funda a confiança em si, o direito funda o respeito e a solidariedade funda a estima" (MARCELO, 2011, p. 275). Ricoeur (2006), por sua vez, em uma fenomenologia da mutualidade, aponta o reconhecimento como algo a ser oferecido, não exigido, um modelo de reconhecimento fraterno. Para Marcelo, esse modelo recognitivo, de uma relação intersubjetiva, pode acompanhar o projeto radical de Lévinas (1980), da ética como filosofia primeira e de um reconhecimento centrado no Outro, no qual o "si" é aquele que menos importa, dada uma posição ética altruísta. que resta no jornalismo? Ou, como pergunta Santos (2006, p. 161): "que é, hoje, a consciência do lugar?". Que contemplações consegue a reportagem diante do seu tempo? Como afirma Butler (2011), é preciso retornar ao palco de uma reflexão sobre a própria estrutura do discurso. Ou podemos pressionar para ver onde a palavra pode tomar início. Nesse sentido, a metáfora geográfica pode ser interessante porque o debate exige entender as dobras do processo; e vamos pensar aqui que a alteridade é esse lugar de começar. A figura do Rosto, a partir da filosofia de Lévinas (1980, 2004), impulsiona parte da reflexão. O Rosto é o que resta do encontro, abrindo os possíveis em direção ao diferente. O rosto não é uma imagem, parte do corpo, nem mesmo uma expressão do olhar. É, na filosofia levinasiana, o sentido profundo do humano aberto para a alteridade, em uma incessante correção da assimetria da proximidade.

O reconhecer, reconhecer-se e ser reconhecido estão interconectados e seu fluxo pede, conforme Bhabha (2002, p. 21), a decisão de nos entendermos duplamente: "como descentrados dos processos solidários e como agentes de mudança conscientemente comprometidos". Em qualquer atividade, mesmo que aqui nos seja central pensar o jornalismo, podemos ter o reconhecimento como fundador da sociabilidade, a interpelar a experiência. Um processo reflexivo, pois o reconhecimento é de caráter recíproco, mútuo ${ }^{1}$.

O olhar e a palavra se cruzam; e o exercício da reportagem jornalística pode permitir alcançar as fraturas do tempo, as veredas do espaço e admitir o infinito do Outro, dando a ver também sua incapacidade de oferecê-lo por inteiro. Compete ao repórter o desenrolar do método cujo eixo fundamental é a observação, a sondagem que caracteriza a aproximação e que é o princípio da busca pela complexidade manifesta na partilha do social, conforme argumenta Osorio Vargas (2017). Essa capacidade de produzir algo a partir do método da reportagem, devedora da observação, é, inclusive, "una contribución de nuestra área a las ciencias sociales, porque desde siempre el periodismo atento, profundo y humano ha mirado" (OSORIO VARGAS, 2017, p. 8). Assim, em uma articulação entre os estudos da reportagem e a filosofia, o objetivo deste texto é debater uma ética do reconhecimento e da alteridade no fazer jornalístico. No centro da dimensão tensional do encontro, atravessado pela hospitalidade do acolhimento ao Rosto do Outro, é possível pensar os gestos inaugurais da reportagem destituídos de uma primazia do eu como separação do Outro mantido como Outro? Que elaborações requer uma escrita que seja resposta ética à interpelação do Rosto?

Como argumentam Martino e Marques (2019), a relação com o Rosto não se dá pelo conhecimento ou pela via da representação, mas pela sociabilidade, pela comunicação:

\footnotetext{
O rosto do outro me afirma e torna minha própria existência humana ao solicitar-me uma escuta e, ao mesmo tempo, uma palavra. Sob esse aspecto, o dizer estabelece uma relação entre duas liberdades, afirmando a identidade dos interlocutores. Nos reconhecemos quando interpelados pelo rosto do outro: não se trata de submissão, mas de um comando ou apelo feito de uma identidade à outra. $\mathrm{O}$ rosto, o humano, abre uma fresta na casca do ser, tornando-o refém do outro, do estrangeiro que bate à nossa porta. A exposição ao outro define as identidades e faz com que o outro se torne importante, vital para a existência do eu (MARTINO; MARQUES, 2019, p. 35).
}

O Outro como o compromisso primeiro para a comunicação e o jornalismo, tendo a alteridade como projeto para a produção do conhecimento, pode ser entendido como o convite inegociável que temos de atender neste nosso tempo, momento no qual, inclusive, nossos objetos solicitam "novos sistemas de compreensão e novas formas de ação" (SANTOS, B., 2002, p. 96). O esforço conceitual e reflexivo sugerido busca apoio ainda em Bhabha (2002, p.78-79), ao desenhar seu 
anseio pelo que "altera o curso", aquilo que possa ser a "fundação de possíveis edifícios outros" e que venha tentar dar conta das desafiadoras dinâmicas socioculturais. $\mathrm{O}$ autor reage às ambivalências e à operação por dicotomias e defende uma hibridação futura inevitável, com base em três elementos paradigmáticos: "a interlocução", "o cosmopolitismo" e "a dúvida global produtiva", concluindo que só o abandono das reivindicações identitárias obsoletas dará lugar ao "reconhecimento da diferença na igualdade", com novas práticas políticas fundadas em uma perspectiva pós-colonial, por exemplo.

É por essas perspectivas que procuramos trabalhar a discussão aqui apresentada, tendo o jornalismo como ponto de partida, a reportagem como figura propulsora e o reconhecimento e a alteridade como prismas das construções sugeridas para o debate. $\mathrm{Na}$ costura dessas proposições, acionamos narrativas e reflexões de alguns repórteres em exercícios reflexivos sobre o seu fazer. A figura do rosto é mantida como iluminadora no percurso, imaginando um saber que nasce da proximidade, da desconfiguração de um sentido único, em direção a um gesto de responsabilidade diante do outro.

\section{Desenvolvimento}

Entender aquilo que contata ${ }^{2}$ neste instante o nosso corpo (TAVARES, 2013) é ter claro que "cada lugar é, à sua maneira, o mundo" (SANTOS, 2006, p. 213). Uma dada situação só pode ser abraçada se forem consideradas as relações intersubjetivas que a caracterizam. Na presença do Outro, construímos a compreensão das relações sociais para além da emergência de acontecimentos, o que talvez dê chance a uma nova geografia noticiável e narrável, que tenha força frente à exclusão: "Una mujer que hurga en un bote de basura dice más que todas las cifras. Un hombre tirado en la banqueta, encogido sobre sí mismo, sus latas vacías a un lado, su cuerpo pobre asomándose a través de sus hilachas, debería marcarnos para siempre" (PONIATOWSKA, 2007, p. 97).

Do relato da cronista franco-mexicana Poniatowska, podemos chegar ao ponto em que o Rosto se torna símbolo crucial no pensamento sobre a alteridade. O Rosto está nesse lugar do mundo vivido, integra as partilhas que a paisagem cultural possibilita e, quando acolhido de frente, instala tensão. Nesse lugar da "realidade tensa, um dinamismo que se está recriando a cada momento" (SANTOS, 2006, p. 213), o jogo do reconhecimento é compromisso inescapável ao jornalismo: a multiplicidade, a coexistência da diversidade, o apelo a uma proximidade. E como ensina Lévinas (1980), a proximidade do outro permanece como ruptura diacrônica, resistência do tempo à síntese da simultaneidade.

Segundo Marcos (2011), o reconhecimento surge pela primeira vez na teoria kantiana e com uma função específica no campo teórico: "reconhecer é também identificar, sendo que identificar é ligar, na intercepção entre a capacidade de receber, associada à sensibilidade, e a capacidade de pensar, associada ao entendimento; intercepção que constitui o acontecimento fundador da filosofia crítica" (MARCOS, 2011, p. 63). Lévinas $(1980,2004)$ coloca que o princípio ético absoluto é o cuidado com o outro, que advém da responsabilidade incondicional e infinita como estrutura fundamental da subjetividade:

Em síntese breve, dir-se-á que a incerteza de que fala Lévinas remete não só para a perda da ideia de soberania do Eu, mas também perde a ideia de comunicação como unicidade, como comunidade. A relação intersubjetiva exige tanto a destituição da primazia do eu, como a separação do outro mantido como outro. Por esse motivo, também, a intersubjectividade e a intercompreensão têm uma dimensão tensional, dimensão que é verdadeiro motor de qualquer relação humana. (MARCOS, 2007, p. 115)³.
${ }^{2}$ Rolnik (2006, p. 3) fala da capacidade do campo do sensível que permite mobilizar afetos e apreender a alteridade. Com a expressão "corpo vibrátil”, debate a percepção via todos os órgãos dos sentidos, o que possibilita a vibração com as "forças do mundo".

${ }^{3} \mathrm{Na}$ leitura que sugere Marcos (2007), o encontro rompe com a mesmidade. 
Os encontros com o Rosto do Outro são os encontros ruptura, "que interrompem alguma coisa, que nos interrompem, que nos roubam a pacatez, que não nos deixam indiferentes, mas que fazem a diferença e nos perturbam na nossa identidade, na nossa mesmidade" (MARCOS, 2010, p. 245) ${ }^{4}$. A questão posta é sempre o Outro, pergunta inquietante, convite ao fim da distância, em que pese estar, paulatinamente, constituindo-se como limite à aproximação: "O outro ameaça a inércia do igual, introduz a incoerência, provoca a contradição. O outro, porque é outro, é factor de caos [...]" (MARCOS, 2007, p.133, grifos no original).

Novamente em Bhabha (2013, p. 34), podemos somar pistas para a análise do tema:

\begin{abstract}
El sujeto de reconocimiento es el proceso por medio del cual surge la "agencia" a través de las estructuras mediadoras de la alteridad que constituyen la representación social. Si retrocedemos sobre la exposición que ofrece Taylor de lo que él llama el "carácter fundamentalmente dialógico" de la vida humana, encontraremos que la práctica del reconocimiento comienza por así decirlo, "a mitad de camino". Recién cuando se han establecido estructuras significantes de diálogo intersubjetivo en el nivel de la anonimidad institucional e ideológica pueden los agentes interlocutorios - tú y yo, los "otros" significantes e insignificantes - asumir, con retraso, determinadas identidades en una conversación de relaciones plurales próximas.
\end{abstract}

Desse ponto, emerge o terceiro espaço significante referido pelo pensador. Ele está no intervalo da agência e da identidade e constitui, a partir do pensamento de Arendt (2016), acionada por Bhabha (2013, p. 34), o intangível em meio de "algo del inter-est, que se encuentra entre las personas y por lo tanto puede relacionar-las y unirlas". Sinais desse procedimento podem ser lidos na fala da jornalista portuguesa Coelho:

O que me interessa é recortar cada fragmento dessa imagem e, com uma espécie de lupa, olhar para ela, com uma noção do seu contexto, mas tendo a noção de que ela é absolutamente singular. E isto é político. Ao dar dignidade a cada pessoa, independente do seu contexto, temos que estabilizar um valor inteiro, e isso é político. Isso retira da ficção, do

${ }^{4}$ Defende Marcos (2008, p. 24) que este é um tema central para a comunicação: "implica pensar processos de diferenciação intersubjetivos das identidades e processos de gestação multicultural das comunidades humanas.

Reconhecer, reconhecer-se e ser reconhecido constituem três momentos no trabalho do reconhecimento - trabalho dispendioso que envolve o humano e o não humano, o eu, os outros e as instituições, as culturas, a vida".

${ }^{5}$ Melo (1999) pontua que a subjetividade é apontada como acolhedora de Outrem, numa espécie de hospitalidade, noção importante para a concepção de "morada" em Lévinas. borrão. (COELHO, 2012, p. 161).

O Rosto dá o verdadeiro testemunho do que resta para a história global. Ele opera e produz uma luta que Butler (2011) diz ocorrer no coração da ética, fora do narcisismo e convidando para algo mais importante, pelo gesto de partilha. E "no hay extraños en sí, sino extraños para alguien”, como infere Sabido (2009, p. 31). Coelho (2013) fala, em determinado momento, de Viva México, dos imigrantes e refugiados reunidos na cidade de Ixtepec, vindos da Guatemala, Belize, Honduras e El Salvador, uma mirada possível em direção ao rosto do Outro quando a jornalista é apresentada a eles:

\footnotetext{
"Hoje temos aqui uma pessoa que tem algo em comum convosco: é a primeira vez que está no México”. Apresentam-me. "Quantas pessoas aqui estão pela primeira vez no México?”. Praticamente todos levantam a mão. "Então, já são companheiros em algo".

Alejandro Solalinde sabe que todas estas pessoas terão razões para não confiar em ninguém. Explicar-lhes quem é a estranha que toma notas é uma forma de respeito. [...] E assim a estranha pode ficar invisível.

Não seremos companheiros, mas já estivemos mais longe. Volto as costas, porque me caem lágrimas pela cara (COELHO, 2013, p. 283)
}

Na proposta de Totalidade e Infinito (1980), Lévinas abre quatro ícones da vulnerabilidade: o pobre, a viúva, o órfão e o estrangeiro, não para definir a alteridade, mas para evocar uma subjetividade ${ }^{5}$ responsável pelo outro, categorias às quais Dussel (1998), ao falar da América Latina, acrescenta os excluídos (e as mu- 
lheres) e as vítimas, o indigente e o indígena, maiorias numéricas no continente, porém tratados como minorias.

Segundo Butler (2011, p. 19), "responder ao rosto, entender seu significado quer dizer acordar para aquilo que é precário em outra vida, ou, antes, àquilo que é precário à vida em si mesma”. Nesse campo das relações intersubjetivas, no qual o Outro é questão imperativa, sem deixar de pensar na autonomia do sujeito, Rabinovich (2009) defende a resposta diante da interpelação do Rosto como uma ética heterônoma: "En este cambio de sentido hacia la heteronomía, el problema deja de ser los límites de lo cogniscible (ya no se trata de conocer o reconocer la alteridad) para dar lugar a la responsabilidad para con el otro" (RABINOVICH, 2009, p. 43). É também testemunhar pelo Outro se assim for necessário, completa. Distante de um pensamento hegemônico de mascarar a subjetividade, ela é acolhida para que um projeto de narrar se concretize, como indica Mansano:

Isso significa lutar para imprimir o produto das invenções subjetivas no cotidiano das relações sociais. E, para isso, cabe-nos a difícil tarefa de acolher a diferença como parte integrante da vida. Diferença a partir da qual o outro, em seus movimentos de diferenciação complexa e na sua dimensão mais viva, possa existir sem ser reduzido a um cumpridor de novas normas universalizadas. (MANSANO, 2009, p. 116)

O pano de fundo de toda discussão pressupõe um "falar com", não um movimento que em sentido amplamente difundido prega um "falar por". Entretanto, considerada a radicalidade do Rosto e o que nasce do encontro e da interação, podemos também entender o dizer do jornalista desde a experiência via o relato daquilo que resta do encontro, em que podemos incluir o pensamento sobre o testemunho e a ação subjetiva do jornalista. Nessa toada, Serelle (2012, p. 183) argumenta que tais narrativas reforçam "a verdade do narrado", não vêm por comprometê-la, pois logram estabelecer uma relação de confiança e de intimidade com o leitor. E, em outro momento, refere que a presença aberta do sujeito, para além do molde da reportagem, ingressa de outro modo no circuito da experiência porque a própria experiência do narrador torna-se parte da narrativa (SERELLE, 2009). Ademais, como propõe Peres (2017, p. 167), o espaço do testemunho é potencial transformador e pode abrir um intervalo para o inventário de existências, um jornalismo que vai ao encontro "das raras palavras" e dos "rastros" dos sujeitos:

[...] a aposta em uma inversão no estatuto do testemunho do qual o jornalismo é tributário em sua chave da "matriz de verdade presumida" (CASADEI, 2013) para afirmá-lo enquanto matriz de lacuna de verdade. No jornalismo sempre preocupado em comprovar dados e fechar todos os vazios, quase sem deixar espaço para o Outro que lhe dirige a palavra ou sobre quem fala, é provável que sublinhar a "lacuna" como força motriz dessa atividade seja visto quase como uma heresia.

Em diferentes escritos, Medina (2006) estabeleceu essa discussão para a reportagem pela proposta interdisciplinar de entender o jornalismo no "signo da relação". Segundo ela, essa sensibilidade da relação é estímulo a uma inteligência plena que organiza a acolhida, as ideias, a expressão para transmutar o estado das coisas. O jornalista brasileiro Castelo faz a defesa do trabalho de diálogo e por uma coragem, pela capacidade de ouvir e "[...] suportar a presença imprevista do outro, as surpresas que nos oferece, a desarmonia de suas ideias" (CASTELO, 2007, p. 17). E complementa: "é chegar de mãos vazias e aceitar o que me dão. Entregar-me, em vez de esperar que o outro se entregue. Desarmar-me, ainda que seja para encontrar o que não desejo encontrar" (CASTELO, 2007, p. 17). Para a jornalista brasileira Eliane Brum (MARIANO, 2011), é esse um gesto de produzir 
documentos do cotidiano a partir de histórias reais e fruto de um ouvir alargado, no exercício da escuta ${ }^{6}$.

A reportagem é um fazer de interface, não está pelos limites, mas surge na porosidade das fronteiras do jornalismo, da literatura e das ciências sociais, quando então logra ser relato jornalístico não condicionado sobre um tema. Aqui, pensamos que a aproximação com a filosofia possa justamente complexificar a compreensão dos gestos que são basilares para sua construção. Emergem daí expressões heterotópicas das coexistências que tornam possíveis os lugares dos sujeitos e o seu lugar nas narrativas, permitindo identificar o gesto de reconhecimento como força motriz no jornalismo, pretendido aqui como narrativa que pode abrir “a possibilidade do possível” (MARCOS, 2007).

Em via crítica a essa tendência de pensamento, como aponta Baptista (2003), podemos ser alertados sobre uma rigidez no discurso jornalístico, historicamente automatizado, que não abriria tal espaço ao desafio da alteridade. Isso também nos remete à afirmação de Butler (2011), assinalada no início do texto, sobre a estrutura do discurso. Baptista recupera um apontamento de Lévinas:

Pergunto-me se podemos falar de um olhar voltado para o rosto, porque o olhar é conhecimento, percepção. Penso antes que o acesso ao rosto é um primeiro momento ético. Quando se vê um nariz, os olhos, uma testa, um queixo e se pode descrever, é que nos voltamos para outrem como um objeto. A melhor maneira de encontrar outrem é nem sequer atentar na cor dos olhos! Quando se observa a cor dos olhos não se está na relação com outrem. A relação com o rosto pode, sem dúvida, ser denominada pela percepção, mas o que é especificamente rosto não se reduz a ele (LÉVINAS, 1998, p. 77).

Para a pesquisadora, em termos gerais, seria possível constatar que o jornalismo não se interessa pelo "incontível”, está preso, quase sempre, “à cor dos olhos”. Essa perspectiva faz lembrar a fala de Roseninho, porta-voz da terra indígena Sawré Muybu, às jornalistas da Agência Pública de Jornalismo Investigativo no Especial Tapajós, série de reportagens que toca no desejo de reconhecimento e no direito de demarcação das terras que abrigam o seu povo: "O que vocês querem perguntar? Vocês querem saber a história Munduruku? Eu posso contar: o cachorro é o homem, a mulher é o peixe. Me diz como vocês vão entender isso? Por isso que eu digo: vocês nunca vão saber" (ARANHA; MOTA, 2016, online).

Outra vez recordando Lévinas, vamos saber que o rosto não é visto, adverte o filósofo. "Ele é o que não se pode transformar num conteúdo, que nosso pensamento abarcaria; é o incontível, leva-nos além." (LÉVINAS, 1998, p. 78). Trata-se, portanto, de pensar amplamente o processo de observação ao qual fazemos referência ao falar da reportagem, uma vez que a crítica demarca que narrar é gesto imperfeito. Não há totalidade a ser apreendida, escreve Carvalho (2014, p. 140), "mas fragmentos que deixam ver - ou ocultam - a riqueza e a multiplicidade da vida social". Isso não diminui a capacidade de mediação, pois está na narrativa um conhecimento do mundo, defende Ricoeur (2010a, 2010b), uma vez que ela é mediadora entre um ponto de partida e um ponto de chegada, ou entre uma determinada configuração de mundo e outra. Merece registro, grande nome dos estudos da narrativa, Ricoeur sublinha a reciprocidade do reconhecimento como a exigência ética mais profunda.

Nos distintos caminhos para contornar os desafios dessa discussão, po-

${ }^{6} \mathrm{Na}$ sintonia do pensamento de Lévinas, trata-se do diálogo na alteridade. Eu não possuo o outro, não o submeto. A comunicação se dá porque me esvazio exponho-me ao outro. demos também tomar a alteridade pelo conceito de outridade, como postulam Freitas e Benetti (2017, p. 12), entendendo-o como um "modo de existência que resulta da articulação do 'eu' com a identidade do outro". E vai nessa direção porque o repórter é também "um ser no mundo", mas como sujeito relacional, na esteira da noção de coexistência, transforma-se em "um ser no mundo com o outro" (FREITAS; BENETTI, 2017, p. 14). Por fim, o que se pode alcançar no exercício do jornalismo, afirmam, é uma outridade relativa, uma vez que a 
outridade plena nos escapa. No âmbito relativo, no entanto, ela é já "um campo aberto de possibilidades para alcançar o conhecimento que se deseja ter sobre 'o outro"' (FREITAS; BENETTI, 2017, p. 16), pois os sujeitos singulares em relação adentram no complexo das semelhanças e diferenças. O resultado é uma tensão que, dizem, "não resulta em equilíbrio, mas no balanço do que é diferente e semelhante, a cada vez que o 'eu' e o 'outro' se percebem" (FREITAS; BENETTI, 2017, p. 23). Esta é uma importante contribuição para tensionar a largo a alteridade no jornalismo.

Uma via possível é trilhar o campo de uma epistemologia do jornalismo que venha desse fazer que justamente experimenta a tensão dos diferentes possíveis fragmentários (FOUCAULT, 2009), narrativas dispersas que podem transcender um tradicional tratamento de personagens e fatos num contexto específico. Os possíveis fragmentários são a profusão de lugares e espaços para falar com as vozes, não por elas, e alargar a compreensão sobre discursos e sujeitos. É pensar que dentro dos possíveis está o horizonte de uma "outra escritura", a partir da heterotopia, a imagem conceitual que traduz a coexistência de um "grande número de mundos possíveis", ou simplesmente espaços incomensuráveis que são justapostos ou superpostos uns aos outros. Neles podemos ver narrares jornalísticos outros ${ }^{7} \mathrm{e}$ fugas que a narrativa proporciona rumo ao diferente. Três ponderações ajudam a estabelecer esses patamares. A primeira, de Medina (2014, p. 47):

A narrativa da contemporaneidade se assina na escritura; não importa qual o código, ela pode se afirmar como polifônica e polissêmica, dialógica e dinâmica, interrogativa e inquieta. [...] A ação social se faz presente: a narrativa se cumpre tanto na espiral dos afetos quanto na esfericidade dos argumentos. Poética e racionalidade mobilizam a plenitude inteligente da transformação do real - o caos funda um cosmos.

\section{A segunda, recuperada de uma proposição de Resende (2009, p. 38):}

O jornalista como protagonista do ato, quando se reposiciona no lugar do humano, cria possibilidades de encontro. Articulando-se no tecido da vida, ele deixa, através do texto, de ocupar o lugar de dono da lei, para tornar-se um observador, tanto quanto o é aquele para quem escreve. Ainda que seja dado ao primeiro o privilégio da escrita, ele não faz sua a voz do outro e nem se propõe, tão-somente, a parafrasear suas fontes, como acontece com o texto jornalístico que nada mais faz do que obedecer às regras do discurso dado como legítimo.

Nesses modos de acolhida do jornalismo, a narrativa não é circulada apenas como modalidade textual, tampouco pode ser traduzida somente por uma técnica. A força do fazer está no manejo dos procedimentos a partir de um projeto humano. A terceira visada é a oferecida por Vargas (2017, p. 71-72):

Así, la metodología del reportaje está compuesta por el mirar, el explorar, el descubrir y el volver a mirar, y desde allí se funda un periodismo de la vida [...] una profesión transcultural que piensa los problemas que la realidad plantea, y que se pregunta tanto como la ciencia. Siguiendo a Werner Heisenberg y su principio de incertidumbre, podemos decir que el acto mismo de observar cambia lo que se está observando - la mirada altera el objeto observado -; así, las ciudades son los libros que leerán los paseantes reporteros [...] libros reportaje que son metáforas de escena viva o metáforas del mundo cotidiano, confrontadas con las particularidades del contexto histórico, social, cultural y con sus impresiones, ya que la lectura en un diálogo, imagen que nos hace volar en nuestra imaginación.

Por consequência, considerar a narrativa nos contornos aqui destacados é lembrar da reportagem como centro do fazer jornalístico, mas dizer que para sua existência há um gesto que é inaugural, que a antecede e tem o destino de transbordar o relato. É rememorar que a narrativa está no complexo universo
${ }^{7}$ Para Baptista (2003, p. 110), "talvez exista ainda no mundo um jardim secreto, uma espécie de Xangrilá, onde verdadeira face do 'eu' pessoa se possa dar a ver: seja a ideia de Deus no rosto de alguém, ou a alma que habita o espectro errante. Será, porém, um lugar bem distante da geografia dos media”.. 
de relações entre os mundos do autor, do texto e do leitor, exigindo um princípio dialógico que permeie entendimentos sobre o jornalismo, os encontros e rupturas que sua escritura pode instalar, bem como ampliar o olhar sobre os modos de inscrição dos sujeitos no seu tempo. Como reflete a jornalista Coelho (2012, p.160), "aquela pessoa tem uma história. Então, este é um sentido político, se quisermos ter um sentido político, que é que não existe eu e o outro, não existimos nós e eles, porque cada pessoa é cada pessoa". Em outro momento, igualmente reflete sobre o Outro e o fazer reportagem; e percebemos nele mais uma vez a possibilidade da alteridade como projeto: "Não sei o que seja a nossa gente, mas a minha gente inclui brasileiros, palestinianos, israelitas, afegãos, mexicanos, açorianos ou transmontanos, e é com todos eles que escrevo, seja de onde for" (COELHO, 2014, online).

Somos levados de novo ao radical da inter-relação entre os sujeitos como centro da comunicação. Para França (2010), estamos falando de uma dinâmica experiencial calcada em um duplo movimento: "um sofrer (ser afetado) e um agir (re-agir ou agir em consequência). A experiência inclui uma dimensão de passividade: eu 'sofro' a afetação do outro sobre mim; aquilo a que sou exposto me afeta, suscita minha emoção" (FRANÇA, 2010, p. 42). Assim vislumbrada, a comunicação está assentada nesse lugar do Outro, como sinalizado anteriormente: "O estar em comunicação, estabelece um contexto distinto: a situação de interação e a consciência da percepção do outro cria um novo coletivo - na relação com o outro,

${ }^{8}$ Não podemos perder de vista que o fazer jornalístico se dá em quadros de disputas de poder, constrangimentos e jogos de enquadramento. Ainda assim, a discussão aqui posta está mais conectada ao nascimento da reportagem a partir da figura do repórter diante do Outro. Sem idealizar determinados espaços, no entanto, não podemos ignorar movimentos que são gestados no interior do próprio campo profissional, com a criação de lugares outros para o narrar. Nossa investigação do tema tem compreendido livros escritos por jornalistas e espaços de reportagem que funcionam em condições não hegemônicas (agências independentes de jornalismo, coletivos de profissionais ou mesmo organizações não governamentais para reportagem) como lugares de tensionar o próprio jornalismo e sua escritura, apesar de haver aí, também outras limitações, como a dimensão de sua circulação e acesso ampliado do que produzem, por exemplo. já não se trata de um e de outro, mas dos dois tomados em conjunto" (FRANÇA, 2010, p. 46). A experiência social, teoriza a pesquisadora, porta um fato fundador: "a existência do olhar do outro, a imprevisibilidade da intervenção do outro e a possibilidade/necessidade dos sujeitos de se colocar no lugar do outro" (FRANÇA, 2010, p. 47). Habitar esse lugar e deixar-se guiar pelo gesto do reconhecimento termina por fazer com que, pela linguagem, possamos acolher. O Outro pode ter morada se nos abríssemos a esse lugar:

\footnotetext{
O que vem perturbar a tranquilidade desse recolhimento é o Outro ou Outrem, visto que, enquanto inteiramente outro, paralisa a posse que ele contesta por sua "epifania" no rosto. É nesse momento que surge o acolhimento: acolho outrem que se apresenta em minha casa abrindo-lhe minha mirada. Esse questionamento de mim, coexistivo da epifania do rosto do Outro, é para Lévinas a própria linguagem. A oferta do mundo a Outrem se faz pela linguagem, entendida nesse sentido como uma dádiva. (MELO, 1999, p. 126).
}

Toda a reflexão também deve considerar a leitura que Derrida (2008) faz da obra de Lévinas, quando sublinha uma dialética entre o Dizer e o Dito, fundamental para tensionar os possíveis e os limites do jornalismo. O Dizer abarca o momento da relação ética, do encontro radical com o Outro, como já mencionado. O Dito, por sua vez, é posterior. É a responsabilidade para com o Outro transmutada nos discursos da igualdade, da equidade e da justiça, por exemplo, nos quais deve estar preservada a radicalidade do Dizer original. No seio do que buscamos tomar como gesto fundador da reportagem, portanto, essa compreensão se torna chave, bem como revela em que sentido ou momento a falha se processa. Em uma proposta de escrita jornalística cujo projeto seja a alteridade, que tensione e seja tensionada pela hospitalidade, o Dizer, não poderá apagar o clamor do Rosto por meio da representação ${ }^{8}$ que oferta desse Outro, quando reduz o Outro ao mesmo.

Com o intuito de pensar "possíveis edifícios outros" para o enfrentamento das questões que dizem respeito ao panorama aqui trabalhado, ao acolher a radicalidade de pensar o Outro, como propõe Bhabha $(1998,2002)$, podemos ferir os acontecimentos na temporalidade contingente do significante, expor caráteres históricos, particulares e singulares, pretendendo suplantar a obliteração dos su- 
jeitos na mera cadeia de acontecimentos. E é uma discussão mais além da humanização ${ }^{9}$ do relato porque está, como sugerido, no terreno da sua fundação.

\section{Considerações finais}

Butler (2010, p. 27) defende que, no rosto do outro, há algo de irrepresentável "que nós, não obstante, perseguimos representar e esse paradoxo deve ser absorvido nas representações que realizamos". Desse modo, se aproximarmos as palavras de Butler da reflexão sobre a reportagem, vamos pensar que essa representação (ou essa narrativa) "deve não apenas falhar, mas deve mostrar sua falha" (BUTLER, 2010, p. 27). É o alcançar a outra margem que permitiria ao repórter dizer do infinito do Outro na própria impossibilidade de fazê-lo, todavia dizer por que o Outro o afeta.

Na mirada ao sul que oferece B. Santos (2002), chamando para uma sociologia das ausências e pela valorização da experiência, podemos acolher essas relações comunicacionais também em seu sabor geográfico, pois são geradas no lugar, em uma ecologia, resultantes do meio social e do ambiente; sua essência terá de ser horizontal, portanto. Se o projeto de partida é a alteridade, estamos em um mesmo "entorno", o que, para o autor, aponta ao "reino da liberdade". A consciência do lugar, deixar-se alcançar, manter a contemplação de que a alteridade e, portanto, a face do Outro, é também lugar, gera a consciência de mundo. Nas palavras de Paz $(1993,1995)$ igualmente podemos recordar que ser um (mesmo) é sempre chegar a ser outro, esse outro que somos como promessa ou possibilidade de ser. E então dar de frente com o Rosto e oferecer abrigo. Assim, passar do Dizer ao Dito é passar de uma margem a outra e é o próprio sentido do percurso, marcado pelo que resta de um no outro.

O processo de nascimento e vida da reportagem é movimento, aparece pelos laços dos "signos en acción, donde la 'crisis' es un despertar de los tiempos múltiples y de los sentidos” (OSORIO VARGAS, 2017, p. 54). Ler e escrever são atividades cruzadas e interdependentes:

Este processo metafórico (e metonímico) decorre da dimensão relacional da linguagem que se exprime na transfiguração do mesmo em alteridade possível. Olhar é ver para além do que se vê, porque a atividade de identificação e reconhecimento faz apelo a categorias anteriores e projecta-se em nomes e expressões diferentes: parecendo repetir é, de facto, de diferenciação que se trata. Imaginar é construir imagens mais do que copiar modelos, sendo que toda a cópia é produção de um outro de si. (MARCOS, 2011, p. 69)

Segundo Carvalho (2014), a comunicação pode, então, ser um "mapa” a estudar a realidade em mutação. "Apresentação experimental do mundo, que põe continuamente a realidade à prova" (MOTTA, 2012, p. 220), no âmbito da experiência partilhada, a narrativa sonda de forma intermitente o tempo e o espaço, alimentando a produção de novos sentidos. Se a alteridade é aceita em sua força, os objetos mudam e propõem “diferentes geografias" (SANTOS, M., 2002, p. 96). Para esse autor, há então uma alteração do valor do objeto, ainda que materialmente seja o mesmo, porque a teia de relações na qual está inscrito opera sua metamorfose, fazendo com que seja substancialmente outro. Estará sempre em criação uma nova geografia.

$\mathrm{Na}$ discussão aqui pretendida, é central pensar que a narrativa jornalística poderá abrir o humano, carregada da alteridade radical, se compreendermos sua semente como uma resposta ética à interpelação do Rosto. E, então, ocupar a geometria de uma escrita que faça trabalhar a hospitalidade, isto é, que reverbere o reconhecimento como gesto fundador. E, ao fazê-lo, tensione a estabilização que tradicionalmente viria a oferecer ao representar o Outro.
${ }^{9}$ Pereira Júnior evidencia que o olhar sobre o personagem não deve estar preso a incidentes ou descobertas ímpares: "Humanizar um relato tem um sentido mais amplo que tudo isso. É resistir à tentação de estandartizar ou de precipitar análise sobre uma pessoa - mas, o que é mais complicado, não reduzir os significados possíveis que retratamos na história. Noticiar com frieza protocolar é um ato desumanizante, seja o alvo da apuração uma pessoa, cena ou história" (PEREIRA JÚNIOR, 2010, p. 96). Certamente essa é uma contribuição importante. $\mathrm{O}$ reconhecimento, contudo, podemos defender, extrapola uma vontade de humanizar o relato pois é visto aqui como propulsor da ação de reportagem. 
Narrar a partir do gesto do reconhecimento é um interpretar que significa caminhar ao mundo aberto pelo que miramos, se atentamente miramos, se fazemos saber pelo deslocamento, esse lugar da acolhida em direção ao mundo. Refletimos assim que a fundação da reportagem se encontra, em essência, no gesto do reconhecimento (hospitalidade) e o percurso que aí se coloca em marcha. Ao sabor da prosa de Guimarães Rosa em Grande Sertão: Veredas, Resende (2015, s/p) costura que o real está na travessia, na tessitura, relembrando que a comunicação não deve visar uma doxa, porém ser espaço do paradoxal: "não é como a coisa é, mas como a coisa se dá, sendo que isso não é somente apresentar os dois lados; narrar é estar no mundo e estar no mundo é conflito". Segundo ele, é preciso que a narrativa deixe transparecer esses modos de estar no mundo. Para tanto, vai concluir com inspiração em Jaques Ranciére: "não é sair do lado de cá para aparecer o lado de lá. É dar a ver o que torna isso possível. Não é 'eu' ou o 'outro', é o embate" (RESENDE, 2015, s/p).

A breve elaboração aqui posta é um percurso tentativo e inspirado em tal provocação e em outra, anterior, ao convidar para que sejamos produtores de um pensamento problema, e não de um pensamento solução, quando se faça trabalhar a chance de outras perguntas e outros percursos como potência (RESENDE, 2014). E vamos por concordar com a poesia de Tavares (2009, p. 11), em suas Breves notas sobre as ligações: "Nem sempre a teoria vem da vontade. Por vezes vem do desligar da vontade. Esquecido da intenção, o homem conhece. Como alguém que cai".

\section{Referências}

ARANHA, A.; MOTA, J. A batalha pela fronteira Munduruku. Agência Pública, São Paulo, 2016. Disponível em: <http://apublica.org/2014/12/batalha-pela-fronteira-munduruku>. Acesso em: 4 maio 2020.

ARENDT, H. A condição humana. 16 ed. Rio de Janeiro: Forense Universitária, 2016.

BAPTISTA, C. Os outros do jornalismo. Media \& Jornalismo, n. 3, p. 103-11, 2003.

BHABHA, H. Democracia des-realizada. Revista Tempo Brasileiro, n. 148, p. 6780, jan./mar. 2002.

BHABHA, H. Nuevas minorías, nuevos derechos: notas sobre cosmopolitismos vernáculos. Buenos Aires: Siglo XXI, 2013.

BHABHA, H. O local da cultura. Belo Horizonte: UFMG, 1998.

BRUM, E. Os vampiros da realidade só matam pobres. In: VARGAS-LLOSA, M. et al. (org.). DIGNIDADE! - nove escritores vivenciam situações-limite e relatam o comovente trabalho da organização Médicos Sem Fronteiras. São Paulo: Leya, 2012.

BUTLER, J. Vida precária. Contemporânea, ed. 1, p. 13-33, jan./jun. 2011.

CARVALHO, C. A comunicação como metáfora para compreensão do social. Líbero, v. 17, n. 34, p. 131-144, 2014.

CASTELLO, J. A literatura na poltrona. Rio de Janeiro: Record, 2007. 
COELHO, A. L. Corta-e-cola até à derrota final. Atlântico Sul, 2014. Disponível em: <http://blogues.publico.pt/atlantico-sul/2014/07/27/corta-e-cola-ate-a-derrota-final>. Acesso em: 4 maio 2020.

COELHO, A. L. Uma ponte entre a escrita e o mundo (entrevista). In: MAROCCO, B. O jornalista e a prática - entrevistas. São Leopoldo: Unisinos, 2012.

COELHO, A. L. Viva México. Rio de Janeiro: Tinta-da-china Brasil, 2013.

DERRIDA, J. Adeus a Emmanuel Levinas. São Paulo: Perspectiva, 2008.

DUSSEL, E. Ética de la liberación. Madrid: Trotta, 1998.

FRANÇA, V. Impessoalidade da experiência e agenciamento dos sujeitos. In: LEAL, B. S; GUIMARÃES, C.; MENDONÇA, C. (orgs.). Entre o sensível e o comunicacional. Belo Horizonte: Autêntica, 2010.

FREITAS, C.; BENETTI, M. Alteridade, outridade e jornalismo: do fenômeno à narração do modo de existência. Brazilian Journalism Research, v. 13, n. 2, p. 10-29, 2017.

FOUCAULT, M. Estética: literatura e pintura, música e cinema. 2 ed. Rio de Janeiro: Forense Universitária, 2009. (Ditos e Escritos, III).

GUIMARÃES, C.; LIMA, C. Ser-em-comum: Notas para uma aproximação entre a Ética de Lévinas e a Episteme comunicacional. Eco-Pós, v. 16, n. 1, p. 76-89, jan./abr. 2013.

LÉVINAS, E. Entre nós: ensaios sobre alteridade. Petrópolis: Vozes, 2004.

LÉVINAS, E. Ética e Infinito. Lisboa: Edições 70, 1998.

LÉVINAS, E. Totalidade e infinito. Lisboa: Edições 70, 1980.

MANSANO, S. R. V. Sujeito, subjetividade e modos de subjetivação na contemporaneidade. Revista de Psicologia da UNESP, v. 8, n. 2, p. 110-117, 2009.

MARCELO, G. O que seria um reconhecimento sem a exigência de reciprocidade? Levinas, Ricoeur e a utopia de um reconhecimento centrado no outro. In: MARCOS, M. L.; COUTINHO, M. J.; BARCELOS, P. Emmanuel Levinas: entre reconhecimento e hospitalidade. Lisboa: Edições 70, 2011, p. 273-288.

MARCOS, M. L. Comunicação, experiência e a questão do reconhecimento: a alteridade radical no pensamento de Lévinas. Entrevista. Intercom. Revista Brasileira de Ciências da Comunicação, v. 33, n. 2, p. 241-251, 2010.

MARCOS, M. L. Identidade narrativa e ética do reconhecimento. Etudes Ricoeurienes/Ricoeur Studies, v. 2, n. 2, p. 63-74, 2011.

MARCOS, M. L. Princípio da relação e paradigma comunicacional. Lisboa: Colibri, 2007.

MARCOS, M. L. Reconhecer, reconhecer-se, ser reconhecido. In: MARCOS, M. L.; MONTEIRO, A. R. Reconhecimento - do desejo ao direito. Lisboa: Colibri, 2008. p. 23-56. 
MARIANO, A. Eliane Brum e a arte da escuta. Em Questão, v. 17, n. 1, p. 299-313, 2011.

MARTINO, L. M. S.; MARQUES, Angela Cristina Salgueiro. A comunicação como ética da alteridade: pensando o conceito com Lévinas. Intercom, v. 42, p. 21-40, 2019.

MEDINA, C. Atravessagem - reflexos e reflexões na memória de repórter. São Paulo: Summus, 2014.

MEDINA, C. O signo da relação. Comunicação e pedagogia dos afetos. São Paulo: Paulus, 2006.

MELO, H. B. O rosto do outro: a morada como acolhimento em Lévinas. Síntese, v. 26, n. 84 , p. $119-126,1999$.

MONTEIRO, A. R. Expressões de reconhecimento. In: MARCOS, M. L.; MONTEIRO, A. R. Reconhecimento - do desejo ao direito. Lisboa: Colibri, 2008. p. 54-104.

MOTTA, L. G. Narrativas jornalísticas e conhecimento de mundo: representação, apresentação ou experimentação da realidade. In: PEREIRA, F.; MOURA, D.; ADGHIRNI, Z. (orgs.). Jornalismo e sociedade: teorias e metodologias. Florianópolis: Insular, 2012. p. 219-241.

PEREIRA JUNIOR, L. C.. Apuração da notícia: métodos da investigação na imprensa. 3 ed. Rio de Janeiro: Vozes, 2010.

PONIATOWSKA, E. Luz y luna, las lunitas. México: Ediciones Era, 2007.

OSORIO VARGAS, R. H. El reportaje como metodologia del periodismo. Una polifonia de saberes. Medellín: Editorial Universidad de Antioquia, 2017.

PAZ, O. El labirinto de la soledad. Bogotá: Fondo de Cultura Económica, 1993.

PAZ, O. Nosotros: los otros. Claves de Razón Práctica, v. 55, p. 2-13, set. 1995.

PERES, A. C. M. A. O que resta dos fatos: testemunho e guinada afetiva no jornalismo. 2017. 182 p. Tese (Doutorado Comunicação Social) - Universidade Federal Fluminense, Rio de Janeiro, 2017.

RABINOVICH, S. Alteridade. In: SZURMUK, M.; IRWIN, R. M. Dicionário de estudios culturales latino-americanos. México: Siglo XXI Editores: Instituto Mora, 2009. p. 43-46.

RESENDE, F. O jornalismo e suas narrativas: as brechas do discurso e as possibilidades do encontro. Galáxia, v. 18, n. 2, p. 31-43, 2009.

RESENDE, F. Fronteiras epistemológicas da pesquisa em Jornalismo. Conferência. In: CONGRESSO DA ASSOCIAÇÃO NACIONAL DE PESQUISADORES EM JORNALISMO, XX; Notas pessoais; 2014.

RESENDE, F. Quando eu (não) é outro: uma conversa sobre cortes e travessias. Universidade Federal de Santa Maria. Aula inaugural do Programa de Pós-graduação em Comunicação; Notas pessoais; 2015. 
RICOEUR, P. Tempo e narrativa. v. 1. São Paulo: WMF Martins Fontes, 2010a.

RICOEUR, P. Tempo e narrativa. v. 3. São Paulo: Martins Fontes, 2010b.

ROLNIK, S. Cartografia sentimental: transformações contemporâneas do desejo. Porto Alegre: Sulina: Editora da UFRGS, 2011.

SABIDO, O. El extraño. In: LEÓN, E. (org.). Los rostos del Otro: reconocimiento, invención y borramiento de la alteridade. México: Anthropos Editorial: Universidad Nacional Autónoma de México, 2009. p. 25-57.

SANTOS, B. S. Renovar a Teoria Crítica e reinventar a emancipação social. São Paulo: Boitempo, 2007.

SANTOS, B. S. Para uma sociologia das ausências e uma sociologia das emergências. Revista Crítica de Ciências Sociais, n. 63, out. 2002.

SANTOS, M. A natureza do espaço: técnica e tempo, razão e emoção. São Paulo: Editora Universidade de São Paulo, 2002.

SANTOS, M. Da totalidade ao lugar. São Paulo: Edusp, 2006.

SERELLE, M. Jornalismo e guinada subjetiva. Revista Estudos em Jornalismo e Mídia, v. 6, n. 2, p. 33-44, 2009.

SERELLE, M. Profissão repórter revisitado: as dimensões do afeto. In: SOARES, Rosana L.; RODRIGUES, Maira (orgs.). Profissão repórter revisitado. São Paulo: Alameda, 2012. p. 177-187.

TAVARES, G. M. Breves notas sobre as ligações. Lisboa: Relógios d'água, 2009. 